Check for updates

Cite this: DOI: 10.1039/d0tb00407c

\title{
Tunable layer-by-layer films containing hyaluronic acid and their interactions with CD44†
}

\author{
Sara Amorim, (D) *abc Iva Pashkuleva, (D) ab Celso A. Reis, (D) defg Rui L. Reis (D) abc and \\ Ricardo A. Pires (iD *abc
}

\begin{abstract}
We report on the development of layer-by-layer (LbL) constructs whose viscoelastic properties and bioactivity can be finely tuned by using polyanions of different size and/or crosslinking. As a polyanion we used hyaluronic acid (HA) - a multi-signaling biomolecule whose bioactivity depends on its molecular weight. We investigated the interplay between the mechanical properties of the LbL systems built using HA of different sizes and the specific HA-mediated biochemical interactions. We characterized the assembled materials and their interactions with CD44, the main HA receptor, by Quartz Crystal Microbalance with Dissipation (QCM-D), Surface Plasmon Resonance (SPR) and Atomic Force Microscopy (AFM). We observed that the presence of CD44 resulted in the disruption of the noncrosslinked multilayers, while crosslinked films remain stable and bind CD44 in a HA molecular weight and charge specific fashion.
\end{abstract}

Received 13th February 2020

Accepted 18th March 2020

DOI: $10.1039 / d 0 t b 00407 c$

rsc.li/materials-b

\section{Introduction}

Layer by layer (LbL) assembly is the hierarchical and controlled association of oppositely charged polyelectrolytes (PEs). It is usually applied to generate coatings or self-standing membranes relevant for different technological fields. ${ }^{1,2}$ In the biomedical area, biodegradable and biocompatible PEs have been used to generate LbL-based drug delivery systems; ${ }^{3}$ substrates that induce stem cell differentiation; ${ }^{4}$ surfaces promoting cell adhesion and proliferation; ${ }^{2,5}$ and mimics of the extracellular matrix (ECM $)^{6}$ and the cancer microenvironment. ${ }^{5,7}$

One of the most studied LbL systems is built by the sequential deposition of hyaluronic acid (HA) and poly-L-lysine (PLL) (Fig. 1a). ${ }^{8-10}$ PLL is a common polycation used in LbL assembly because of its biocompatibility and the fact that it is usually used as a coating that promotes cell attachment. ${ }^{11,12}$ On the other hand, HA is a negatively-charged, non-sulphated glycosaminoglycan that

\footnotetext{
${ }^{a} 3 B$ 's Research Group, I3Bs - Research Institute on Biomaterials, Biodegradables and Biomimetics, University of Minho, Headquarters of the European Institute of Excellence on Tissue Engineering and Regenerative Medicine, AvePark, Parque de Ciência e Tecnologia, Zona Industrial da Gandra, 4805-017 Barco, Portugal. E-mail: sara.amorim@i3bs.uminho.pt, rpires@i3bs.uminho.pt

${ }^{b}$ ICVS/3B's - PT Government Associate Laboratory, Braga/Guimarães, Portugal ${ }^{c}$ The Discoveries Centre for Regenerative and Precision Medicine, Headquarters at University of Minho, Avepark, 4805-017 Barco, Guimarães, Portugal

${ }^{d}$ i3S, University of Porto, Portugal

${ }^{e}$ IPATIMUP, Porto, Portugal

${ }^{f}$ Department of Pathology and Oncology, Faculty of Medicine, Porto University, Portugal

${ }^{g}$ Institute of Biomedical Sciences Abel Salazar, University of Porto, Portugal

$\dagger$ Electronic supplementary information (ESI) available. See DOI: 10.1039/d0tb00407c
}

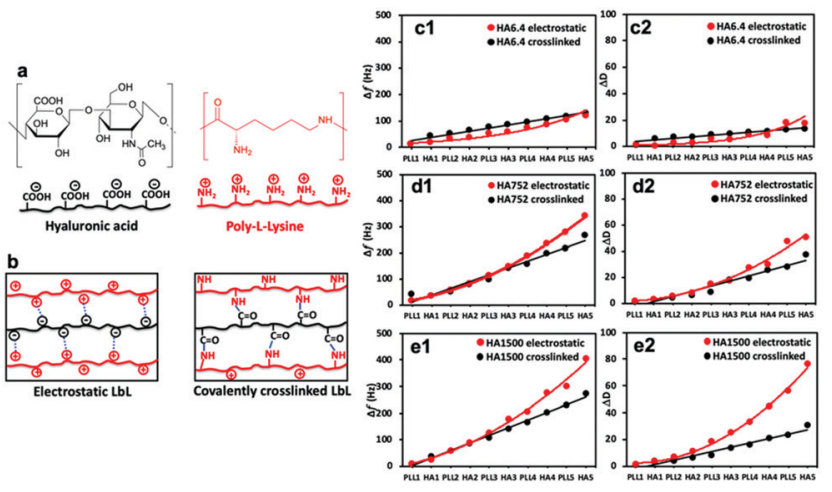

Fig. 1 (a) Chemical structure of the used polyelectrolytes and (b) schematic presentation of their interactions in the two experimental setups. (c-e) QCM-D data (7th overtone) showing changes in (c1-e1) frequency $(\Delta f)$ and (c2-e2) dissipation $(\Delta D)$ for the electrostatic (red) and covalently (black) crosslinked $(\mathrm{PLL}-\mathrm{HA})_{5}$ systems. LbL assembly was executed with PLL $\left(M_{\mathrm{w}}=30-70 \mathrm{kDa}\right)$ and HA of (c) 6.4, (d) 752 and (e) 1500 kDa. Raw data are presented in Fig. S1 (ESI $\dagger$ ).

is one of the main components of mammalian connective tissue. ${ }^{13,14} \mathrm{HA}$ is also an important multi-signalling molecule that interacts with specific cell surface receptors/proteins (e.g. CD44) and regulates different cellular functions. ${ }^{15,16}$ As an example, HA is a key player in cancer cell biology and the acquisition of malignant phenotypes. ${ }^{17}$ In fact, the tumour microenvironment is characterized by excessive deposition of HA. ${ }^{18}$ Its molecular weight $\left(M_{\mathrm{w}}\right)$ is also altered mostly due to the overexpression of hyaluronidases. These changes affect the mechanical properties (usually leading to a higher stiffness) and the biofunctionality of the matrix of the cancerous tissues. ${ }^{19}$ 
Based on the importance of the HA size to its biological signalling, ${ }^{20,21} \mathrm{HA}$ is usually used for the assembly of LbL systems in the biomedical field. ${ }^{22}$ However, whereas HAs of high $M_{\mathrm{w}}$ (e.g. $>100 \mathrm{kDa}$ ) are the most studied, ${ }^{23,24}$ data about short HAs (e.g. HA oligosaccharides $<10 \mathrm{kDa}$ ) are scarce. Moreover, the developed LbL systems are well characterized in terms of physico-chemical properties but the correlation between these properties and the bioactivity of the generated LbL constructs is not thoroughly studied. In this work, we use HA of different sizes, not only to modulate the viscoelastic properties of the LbL constructs, but also to impart different bioactivities to these constructs. We provide systematic data about the thickness, stiffness and hydration of the LbL assemblies, as well as on their ability to recognize and interact with CD44 (one of the main HA cell surface receptors), whose overexpression is one of the main cancer markers. ${ }^{25}$

\section{Materials and methods}

\section{Materials}

We studied two PEs: poly-L-lysine hydrobromide (PLL; $M_{\mathrm{w}} \mathrm{S}$ 30-70 kDa) from Sigma-Aldrich, and hyaluronic acid (HA; $M_{\mathrm{w}} \mathrm{S}$ of 6.4, 752 and $1500 \mathrm{kDa}$ ) obtained from Lifecore. For the crosslinking of the multilayers we used $\mathrm{N}$-(3-dimethylaminopropyl)$N^{\prime}$-ethylcarbodiimide hydrochloride (EDC, $\geq 98.0 \%$ ) and $N$-hydroxysuccinimide (NHS) purchased from Sigma-Aldrich. Both PEs and the chemicals were used as received without any further purification.

\section{Methods}

Quartz crystal microbalance with dissipation (QCM-D). Gold-coated AT-cut quartz crystals (QSX301) were placed in a QCM-D flow chamber (E4 instrument, Q-Sense, Sweden). The temperature was set to $25{ }^{\circ} \mathrm{C}$ and a stable baseline was acquired using $\mathrm{NaCl} 150 \mathrm{mM}$ aqueous solution. A PLL solution $(0.5 \mathrm{mg} \mathrm{mL}$ in $150 \mathrm{mM} \mathrm{NaCl}$ ) was injected into the chamber for $15 \mathrm{~min}$. The sensor was rinsed with the $\mathrm{NaCl} 150 \mathrm{mM}$ aqueous solution to remove loosely bound material. A HA solution $\left(1 \mathrm{mg} \mathrm{mL}^{-1}\right.$ in $150 \mathrm{mM} \mathrm{NaCl}$ aqueous solution) was injected into the flow chamber for $15 \mathrm{~min}$. For the crosslinked assemblies, the HA solutions were supplemented with the crosslinking agents (EDC, $400 \mathrm{mM}$, and NHS, $100 \mathrm{mM}$ ). A new washing step was performed, followed by the injection of PLL solution into the QCM-D chamber. The deposition of PLL and HA was repeated until ten layers were obtained, i.e. (PLL-HA) 5 . The adsorption and washing steps were performed with a flow rate of $50 \mu \mathrm{L} \mathrm{min}{ }^{-1}$. The adsorption of CD44 his-tag protein (orb84335), $10 \mu \mathrm{g} \mathrm{mL}^{-1}$ in PBS solution with $1 \%$ BSA, was performed after establishing a baseline with PBS using the same flow rate. All measurements were performed at several harmonics $(n=1,3,5,7,9$ and 11, corresponding to $5,15,25,35,45,55$, and $65 \mathrm{MHz}$, respectively). $\Delta f_{n} / n$ and $\Delta D$ were fitted using the Voigt model for the 5th, 7th and 9th overtones using the Q-Sense DFind software.

Surface plasmon resonance (SPR). SPR full angle scans were performed simultaneously at 670 and $785 \mathrm{~nm}$ with a multi-parametric instrument (MP-SPR), SPR Navi 200 (BioNavis, Finland). As in the case of the QCM-D experiments, the assembly of 5 bilayers was performed and monitored in situ. Each layer was allowed to adsorb for $5 \mathrm{~min}$, with a washing step, using an aqueous $\mathrm{NaCl} 150 \mathrm{mM}$ solution, between the injection of each PE. The CD44 his-tag protein was adsorbed under the same conditions. SPR data for the LbL construction were analyzed using the LayerSolver software (version 1.3.8, Max Planck Institute for Polymer Research, Mainz, Germany), applying the Fresnel equation, using the dual-wavelength method (670 and $785 \mathrm{~nm}$ ). Briefly, the dual-wavelength method correlates linearly the dispersion coefficient and the wavelength changes, which is used to determine the refractive index $(\eta)$ according to the equation:

$$
\frac{\mathrm{d} n}{\mathrm{~d} \lambda}=\frac{\left(n_{785}-n_{670}\right)}{785-670}
$$

In this method, the LayerSolver software automatically fits the obtained data and returns the values for the thickness (Th or $d$ ) and $\eta$. To be able to obtain the Th value from eqn (1), the parameters $(d, \eta)$ were used as dependent variables at 670 and $785 \mathrm{~nm}$, the coefficient $\mathrm{d} \eta / \mathrm{d} \lambda$ being a fixed value, and used as linearly dependent. ${ }^{26}$ Based on the De Feijter equation (eqn (2)), the adsorbed mass $(\Gamma)$ is calculated, considering the SPR measured optical thickness, $\mathrm{Th}_{\mathrm{f}}$, and refractive index, $\eta_{\mathrm{f}}$, of the films:

$$
\Gamma=\frac{\mathrm{Th}_{\mathrm{f}} \times\left(n_{\mathrm{f}}-n_{\mathrm{b}}\right)}{(\mathrm{d} n / \mathrm{d} c)}
$$

where $\eta_{\mathrm{b}}$ is the refractive index of the buffer (RI of water 1.332) and $(\mathrm{d} \eta / \mathrm{d} c)$ is the incremental change in $\eta$ of the solution of the polymers, which was assumed to be $0.15 \mathrm{~cm}^{3} \mathrm{~g}^{-1} \cdot{ }^{27-29}$

Atomic force microscopy. The generated LbL surfaces were analyzed using a JPK NanoWizard 3 (JPK, Germany). The Young's modulus of the films was measured under QI Advanced Imaging Mode using qp-BioAC-CB3 probes (calibrated using the noncontact method in the JPK software; a resonance frequency of $\sim 23-37 \mathrm{kHz}$ and a calibrated spring constant of $\sim 0.065 \mathrm{~N} \mathrm{~m}^{-1}$, NanoSensors, Germany) and the values were obtained by fitting the approach curves with the Hertz/Sneddon model, using a cone tip shape (applying a very short indentation range, $0.5-1 \mathrm{~nm}$, to avoid the influence of the substrate). All the experiments were performed in air, while the surfaces were humidified using a drop of PBS.

$\zeta$-Potential measurements. The $\zeta$-potential of the assembled films was analysed using an electrokinetic analyzer (SurPASS, Anton Paar, Graz, Austria). The (PLL-HA) $)_{5}$ samples were mounted in an adjustable gap cell $\left(1 \times 2 \mathrm{~cm}^{2}\right)$. The gap between the samples was adjusted to apx. $110 \mu \mathrm{m}$ and an electrolyte ( $1 \mathrm{mM} \mathrm{KCl,} \mathrm{a} \mathrm{pressure} \mathrm{of} 400 \mathrm{mbar}$ ) was flowed through the cell. The streaming current $\left(I_{\text {str }}\right)$ was determined at different $\mathrm{pH}$ values within the range of 5.5 to 10 , automatically adjusted by the addition of $\mathrm{NaOH}(0.05 \mathrm{M})$ to the solution. The respective $\zeta$-potential was calculated and averaged over three measurements using Attract 2.0 software, which uses the Smoluchowski equation for calculation of the $\zeta$-potential from $I_{\text {str }}$. 


\section{Theoretical models and equations}

Hyaluronic acid conformation. Depending on the $M_{\mathrm{w}}$ of HA, the radius of gyration $\left(R_{\mathrm{g}}\right)$ and hydrodynamic radius $\left(R_{\mathrm{h}}\right)$ vary. ${ }^{30}$ Accordingly, $R_{\mathrm{g}}$ and $R_{\mathrm{h}}$ were calculated using eqn (3) and (4), respectively:

$$
\begin{aligned}
& R_{\mathrm{g}}=2.35\left(\mathrm{HA} M_{\mathrm{w}} \text { in } \mathrm{kDa}\right)^{0.57} \\
& R_{\mathrm{h}}=0.87\left(\mathrm{HA} M_{\mathrm{w}} \text { in } \mathrm{kDa}\right)^{0.63}
\end{aligned}
$$

Storage and elastic modulus. The viscoelastic properties of the films were obtained using the Voigt model, from which the shear modulus $\left(G^{\prime}\right)$ and the viscous modulus (loss modulus $-G^{\prime \prime}$ ) of each LbL film were determined, as detailed in eqn (5) and (6):

$$
\begin{gathered}
\mu=G^{\prime} \\
\eta^{\prime}=\frac{G^{\prime \prime}}{\varpi}
\end{gathered}
$$

where $\mu$ is the shear modulus (in $\mathrm{Pa}$ ), representing the elastic component of a viscoelastic material, $\eta^{\prime}$ is the dynamic viscosity (in Pa s) and $\varpi$ is the angular frequency $\left(\varpi=2 \pi f_{7}\right){ }^{31}$

Hydration of the films. The hydration (Hyd) of the assembled LbL films was calculated using the following equation:

$$
\% \text { of hydration }=\frac{\left(m_{\mathrm{QCM}-\mathrm{D}}-m_{\mathrm{SPR}}\right)}{m_{\mathrm{QCM}-\mathrm{D}}} \times 100
$$

where $m_{\mathrm{QCM}-\mathrm{D}}$ and $m_{\mathrm{SPR}}$ are the acoustic and optical thickness of the films, respectively. ${ }^{32}$
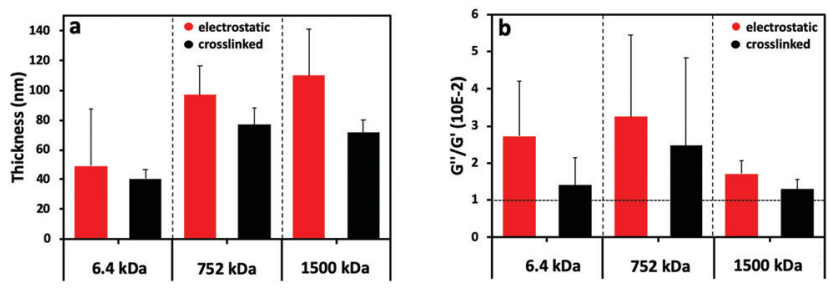

Fig. 2 (a) Hydrodynamic film thickness obtained by fitting the QCM-D data (5th, 7th and 9th overtones) according to the Voigt model and (b) viscoelastic properties shown by the ratio $G^{\prime \prime} / G^{\prime}$ of the (PLL-HA) 5 assemblies prepared with HA of different $M_{\mathrm{w}} \mathrm{s}$.

\section{Results and discussion}

Real time characterization of LbL films generated by the combination of PLL and HA of different $M_{w}$

QCM-D and SPR were used to follow in real-time the construction of the 10-layer films, i.e. (PLL-HA) . QCM-D gives information about the mass adsorption, viscoelastic properties and hydration of the materials. ${ }^{33,34}$ Upon mass adsorption, the frequency of the quartz sensor decreases. Together with changes in frequency $(\Delta f)$, the QCM-D instrument allows simultaneous collection of data related to the energy dissipation $(\Delta D)$, which is intimately related to the presence of water in the adsorbed layer. ${ }^{35}$

We used two sets of experiments: (i) electrostatically deposited

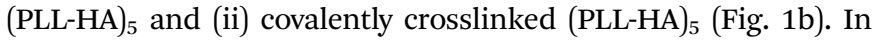
both sets of LbL films we used HA of different $M_{\mathrm{w}}$. The QCM-D results showed that the $\Delta f$ and $\Delta D$ values depend on the size of HA and on the type of crosslinking (Fig. 1c-e).

The (PLL-HA) $)_{5}$ film growth (increased $\Delta f$ and $\Delta D$ values) is directly proportional to the increment of the HA $M_{\mathrm{w}}$ (Fig. 1c1-e1): $\Delta f(\text { PLL-HA6.4 })_{5} \ll \Delta f(\text { PLL-HA752 })_{5} \approx \Delta f(\text { PLL-HA1500 })_{5}$. Previous reports describe exponential growth for LbL films of the PLL/HA combination. ${ }^{36-38}$ This behavior is typical for weak PEs, such as $\mathrm{HA}$, and is related to the diffusion of the PLL chains into the interior of the film. ${ }^{39}$ In accordance with these studies, we also observed exponential growth of the electrostatic LbL films (Fig. 1c-e, red) regardless of the size of the used HA. The crosslinked LbL films behaved differently - they followed linear growth (Fig. 1c-e, black). On one hand, this difference can be explained by the reduced PLL mobility as a result of the crosslinking. ${ }^{9}$ On the other hand, the deposited mass for the crosslinked LbL films is systematically lower and the films are thinner and less dissipative when compared to the constructs built by electrostatic interactions (Fig. 1c2-e2 and 2a, red vs. black, Table 1). These differences are more pronounced for the HA of higher $M_{\mathrm{w}}$ S (i.e. $\mathrm{HA}_{752}$ and $\mathrm{HA}_{1500}$ ) and can be explained either by less deposited material or/and closer packing of the PEs, i.e. formation of less hydrated and denser LbL films as a result of the formation of covalent bonds between PLL and HA. ${ }^{38}$

The storage modulus ( $G^{\prime}$, elastic component) and loss modulus ( $G^{\prime \prime}$, viscous component) were calculated from the QCM-D data (Fig. S2, ESI $\dagger$ ). The ratio $G^{\prime \prime} / G^{\prime}$ gives an indication about the changes in the viscous and elastic component of the

Table 1 QCM-D and SPR parameters obtained for the LbL systems prepared using HA of different $M_{w} s$ (in the presence and absence of crosslinking) and PLL ( $M_{\mathrm{w}}$ of 30-70 kDa). The acoustic film thickness, Th ${ }_{\mathrm{QCM}}$, and mass, $m_{\mathrm{QCM}}$, were determined using the Voigt model; the optical film thickness, Th

\begin{tabular}{|c|c|c|c|c|c|c|c|c|c|c|c|}
\hline \multirow{3}{*}{$\begin{array}{l}\mathrm{HA} \\
M_{\mathrm{w}} \\
\mathrm{kDa}\end{array}$} & \multirow{2}{*}{\multicolumn{3}{|c|}{$\begin{array}{l}\text { Electrostatic LbL } \\
(\text { PLL-HA })_{5}\end{array}$}} & \multicolumn{8}{|l|}{ Crosslinked LbL } \\
\hline & & & & \multicolumn{3}{|l|}{$\underline{(\mathrm{PLL}-\mathrm{HA})_{5}}$} & \multicolumn{5}{|c|}{$\underline{(\mathrm{PLL}-\mathrm{HA})_{5}-\mathrm{CD} 44}$} \\
\hline & $\begin{array}{l}m_{\mathrm{QCM}} \\
\mathrm{ng} \mathrm{cm}\end{array}$ & 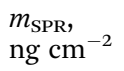 & $\begin{array}{l}\text { Hyd, } \\
\%\end{array}$ & $\begin{array}{l}m_{\mathrm{QCM}} \\
\mathrm{ng} \mathrm{cm}\end{array}$ & $\begin{array}{l}m_{\mathrm{SPR}}, \\
\mathrm{ng} \mathrm{cm}\end{array}$ & $\begin{array}{l}\text { Hyd, } \\
\%\end{array}$ & $\begin{array}{l}\mathrm{Th}_{\mathrm{SPR}} \\
\mathrm{nm}\end{array}$ & $\begin{array}{l}m_{\mathrm{QCM}}, \\
\mathrm{ng} \mathrm{cm}^{-2}\end{array}$ & 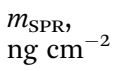 & $m_{\mathrm{SPR}}^{\mathrm{CD} 44}$ & $\begin{array}{l}\text { Hyd, } \\
\%\end{array}$ \\
\hline 6.4 & $5571.8(1861.5)$ & 421.4 & 92.4 & $4340.9(502.0)$ & 669.6 & 84.6 & $10.0(1.450)$ & 5050.6 (1039.9) & 786.7 & 117.8 & 84.4 \\
\hline 752 & $10665.2(3440.3)$ & 1312.4 & 87.7 & $8593.3(1404.4)$ & 1337.9 & 84.4 & $43.9(1.381)$ & $8233.2(1220.0)$ & 1427.5 & 89.6 & 82.7 \\
\hline 1500 & $12494.8(4057.2)$ & 2321.2 & 81.4 & $7882.0(951.2)$ & 1343.2 & 82.9 & $48.8(1.376)$ & $8237.3(484.9)$ & 1431.5 & 106.1 & 82.6 \\
\hline
\end{tabular}
and mass, $m_{\mathrm{SPR}}$, were determined using the multiparameter SPR, based on the equations described in the Experimental section (eqn (1) and (2), respectively); and the film hydration (Hyd) was determined from the $m_{\mathrm{QCM}}$ and $m_{\mathrm{SPR}}$ data using eqn (7). The mass of CD44 was obtained from the difference between $m_{\mathrm{SPR}}$ and $m_{\mathrm{SPR}}^{\mathrm{LbL}+C D 44}$. Standard deviations of the $m_{\mathrm{QCM}}$ values are presented in parenthesis, while in the case of Th refractive indexes are presented in parenthesis 
assembled films (Fig. 2b and Fig. S3, ESI $\dagger$ ). The electrostatically assembled films present a higher $G^{\prime \prime} / G^{\prime}$ ratio than the crosslinked ones, showing a higher contribution of the viscous component (water content) to the properties of the films (Fig. 2b). In the case of the crosslinked films, a sharp decrease in $G^{\prime \prime} / G^{\prime}$ is observed for the shortest HA (6.4 kDa). This behavior is consistent with the conversion from a gel-like assembly to compact film formation. ${ }^{40}$ The assemblies generated with the HA of higher $M_{\mathrm{w}} \mathrm{s}$ presented the same trend but the difference is not significant.

We then used SPR to complement the QCM-D data, and provide information about the whole LbL construct, including water. The optical-based SPR differs from the acoustic QCM-D as it provides information only about the "dry mass" (Fig. S3, ESI $\dagger$ ).

The SPR data showed that the angle shift $(\theta)$ increases with the HA size, following the same trend as the one observed by QCM-D (Fig. 2a), i.e. formation of thicker LbL films by the HA of the highest $M_{\mathrm{w}}(1500 \mathrm{kDa})$ and thinner constructs when assembled using the shortest HA $(6.4 \mathrm{kDa})$ for the electrostatic films (Fig. 3c, red symbols). All crosslinked LbL films are thinner when compared to the respective constructs formed by electrostatic interactions (Fig. 3c, red vs. black symbols). Of note, this thickness difference is less pronounced for HA of $6.4 \mathrm{kDa}$ and increases with the HA size. Another important result is $\eta_{\mathrm{f}}$, which shows a similar material density for all constructs except for the crosslinked LbL film generated using HA of $6.4 \mathrm{kDa}$. The combination of high $\eta$ and low thickness demonstrates densification of these films. ${ }^{41,42}$ Comparing the mass determined by QCM-D $\left(m_{\mathrm{QCM}}\right)$ with the one measured by SPR $\left(m_{\mathrm{SPR}}\right)$ allows us to determine the hydration of the studied layers (Table 1). As expected, all films are highly hydrated, ${ }^{43}$ and the crosslinking reduces significantly $(10 \%)$ the hydration of the LbL films generated using short HA. On the other hand, the hydration of the LbL films generated with $\mathrm{HA}_{752}$ and $\mathrm{HA}_{1500}$ was not affected by the crosslinking. Longer HA is associated with higher $R_{\mathrm{g}}$ (see Table S1, ESI $\dagger$ ) and thus fosters the intramolecular interactions, leading to increased entrapment of water (a higher hydrodynamic radius). ${ }^{44}$ The increased hydrodynamic radius of HA does not compromise its ability
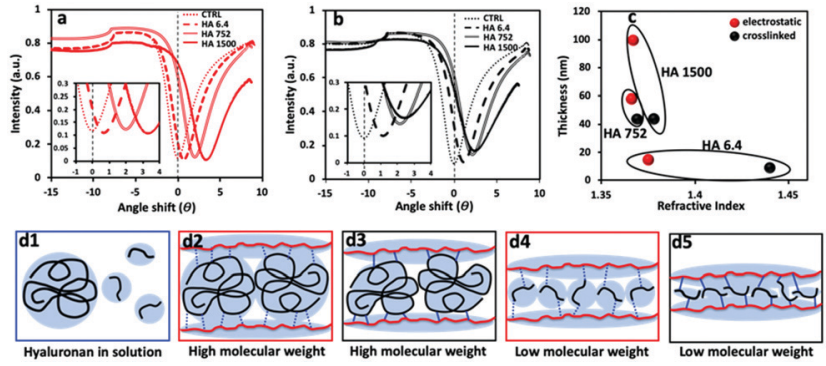

Fig. 3 SPR data for the studied LbL films: reflectivity curves for (a) electrostatically assembled and (b) crosslinked (PLL-HA) $)_{5}$ (c) plot presenting the calculated thickness vs. refractive index for these films. (d) Schematic presentation of the observed differences between long HA chains and short ones: (d1) hydration of HA in aqueous media; electrostatic assembly of (d2) high $M_{w} H A$ and (d4) HA of low $M_{w}$; crosslinked LbL films assembled from (d3) longer HA chains that keep the intramolecularly entrapped water and (d5) short HA. to be chemically crosslinked with PLL as these bonds are mainly mediated by the carboxyl groups exposed on the HA surface.

Altogether these results suggest the existence of size-dependent mechanisms of the interactions between PLL and HA. Previous studies showed that this dependence is due to the mobility of the polycation (PLL). ${ }^{24}$ Herein, we demonstrate that different hydration/dehydration of longer and shorter HA chains plays also a role in this process (Fig. 3d).

In general, it is expected that the reduction of the film thickness observed upon crosslinking will lead to the densification and dehydration of the crosslinked LbL systems as compared to their electrostatic analogues. Indeed, this is the result observed for the constructs assembled from the shortest HA (i.e. $6.4 \mathrm{kDa})$. In the case of LbL systems generated using HA of longer chains, the use of crosslinking does not affect significantly the hydration level.

\section{Mechanical properties of the (PLL-HA) $)_{5}$ systems generated with HA of different $M_{w}$}

To better understand the impact of hydration and crosslinking on the properties of the (PLL-HA) $)_{5}$ LbL systems, we evaluated their mechanical properties by AFM. Of note, the information obtained by AFM is limited to the surface of the construct and differs from the data generated via QCM-D, which presents average values for the whole construct. Another difference is that the AFM measurements are performed through nanoindentation in a direction perpendicular to the deposition plane and to the direction of the HA/PLL fibers, while QCM-D measures $G^{\prime}$ in a direction parallel to the deposited fibers.

In the case of the electrostatically-assembled films we observed a decrease of the Young's modulus with the increment of the HA $M_{\mathrm{w}}$ (Fig. 4). These results are in contradiction to the hydration of these constructs (Table 1), i.e. lower hydration with the increase of the HA $M_{\mathrm{w}}$. However, the surface of the construct (last deposited bi-layer) differs from its bulk and the obtained results are due to the formation of a surface hydration shell that contains water molecules ${ }^{39}$ loosely bound to the HA end-layer and that increases with the HA $M_{\mathrm{w}}$.

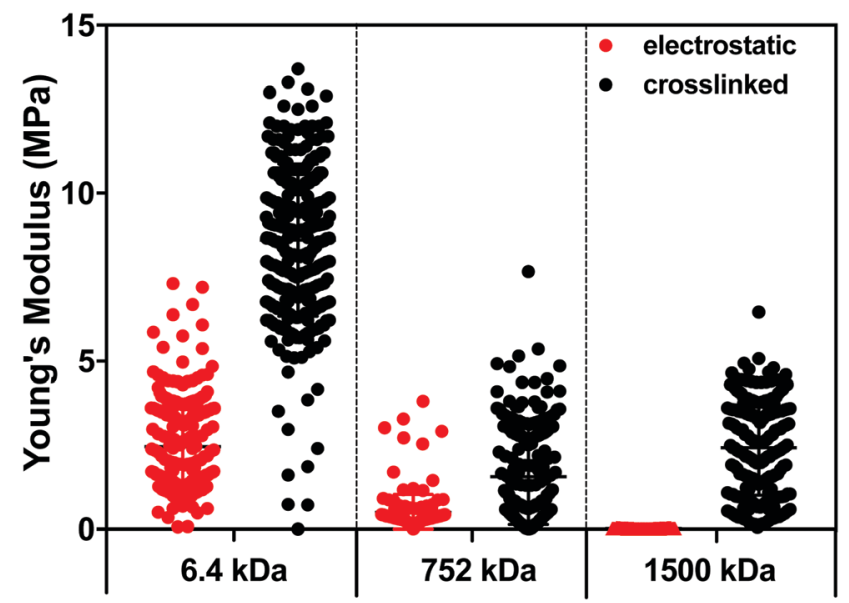

Fig. 4 Young's modulus of the (PLL-HA) 5 LbL films generated using PLL of $30-70 \mathrm{kDa}$ and $\mathrm{HA}$ of $6.4,752$ and $1500 \mathrm{kDa}$. 
The crosslinked LbL systems are stiffer than the respective electrostatic constructs (increased Young's modulus); however, it is observed the same tendency in stiffness as a function of the HA size as the one observed for the electrostatically deposited assemblies, i.e. a decrease in the Young's modulus with the increment of the $M_{\mathrm{w}}$ of HA.

\section{Bioactivity of the LbL systems generated with HA of different molecular weights}

Besides generation of constructs with different mechanical properties, HA of different size can also code different bioinformation. ${ }^{45,46}$ Moreover, HA incorporation in the constructs via crosslinking (covalent interactions) introduces chemical modifications in its main backbone that can also alter the bioinformation coded by this glycosaminoglycan. We then assessed the interactions between the generated LbL films and CD44, one of the main cell surface receptors for HA, using QCM-D and SPR (Fig. 5). $\Delta D / \Delta f$ plots showed a reduction of $\Delta f$ (mass loss) upon the addition of CD44 His-tag protein to the electrostatically assembled systems, independently of the HA size. The SPR data corroborated these results for the LbL films assembled with HA of 752 and $1500 \mathrm{kDa}$ (Fig. 5e and f, red curve) and showed that the specific interactions between CD44 and HA are stronger than the electrostatic interactions driving the LbL assembly and thus result in the partial disassembly of the films. In the case of the system generated using short HA (Fig. 5d, red), we observe an increase in the adsorbed "dry" mass, showing that the reduction of $\Delta f$ and $\Delta D$ (observed by QCM-D) for this system is mainly driven by dehydration/compactation.

The disassembly observed for the electrostatically generated systems is abolished in the crosslinked films: QCM-D and SPR sensograms (Fig. S4, ESI $\dagger$ ) showed the retention of CD44 by these systems, independently of the HA $M_{\mathrm{w}}$ (Fig. 5 and Fig. S1, S4, $\mathrm{ESI} \dagger$ ). Of note, the adsorption of CD44 does not significantly affect the viscoelastic properties of these LbL films. The SPR data allows the quantification of the adsorbed protein and demonstrated a dependence on the $M_{\mathrm{w}}$ of HA (Table 1). The highest retention of CD44 was measured for the crosslinked construct
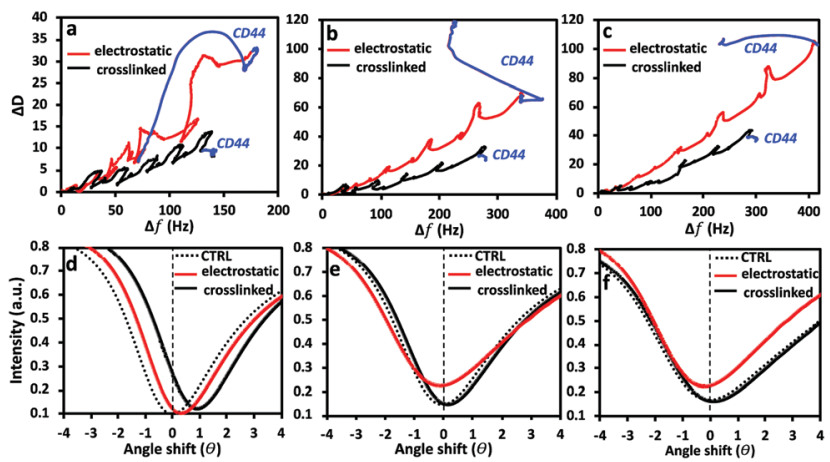

Fig. 5 (a-c) QCM-D $\Delta D / \Delta f$ plots (7th overtone) and (d and e) SPR reflectivity curves $(d-f)$ showing the interaction of CD44-his tag protein with electrostatically deposited and crosslinked (PLL-HA) $)_{5}$ films assembled from HA of different size, i.e. ( $a$ and d) 6.4, (b and e) 752 and (c and f) $1500 \mathrm{kDa}$. In the SPR curves, the black dashed line represents the normalized angle shift of $(\mathrm{PLL}-\mathrm{HA})_{5}$, i.e. the SPR signal of the construct alone. with the shortest HA. This result agrees with the literature reporting an increased affinity of HA of low $M_{\mathrm{w}} \mathrm{s}(3-5 \mathrm{kDa})$ with the transmembrane receptor $\mathrm{CD} 44$, overexpressed in cancer cells. ${ }^{47}$ The higher $\eta_{\mathrm{f}}$ of these LbL films is consistent with a densification of the film upon protein adsorption. When longer HAs (752 and $1500 \mathrm{kDa}$ ) are used for the construction of the crosslinked films, less CD44 is adsorbed. A possible reason for this observation is the different mechanisms of interaction of CD44 with the (PLL-HA) $)_{5}$ systems: while in the films generated using $\mathrm{HA}_{6.4}$, besides the specific affinity between CD44 and HA, the higher amount of PLL available on the surface (as shown by a higher $\zeta$, i.e. $-8.6 \pm 20.9 \mathrm{mV}$, Fig. S5, ESI $\dagger$ ) allows the existence of non-specific electrostatic interactions between CD44 and PLL. In the presence of $\mathrm{HA}_{752}$ and $\mathrm{HA}_{1500}$, CD44 binds almost exclusively to HA, leading to an increment of the adsorbed mass with the augmentation of the HA $M_{\mathrm{w}}$, as a higher number of HA motifs are available at the surface of the LbL systems. In fact, an enhanced and irreversible interaction between CD44 and HA of higher $M_{\mathrm{w}} \mathrm{S}$ has been previously observed. ${ }^{48}$

Altogether, our results demonstrate that electrostatically assembled LbL systems generated from PLL and HA are not feasible solutions to explore specific HA-mediated biomolecular interactions, due to their low stability. Crosslinking of the layers increases the construct biostability and allows quantification of HA-CD44 interactions without disruption of the assembled multilayers. Finally, the bioactivity of these crosslinked systems is also sensitive to the $M_{\mathrm{w}}$ of HA, reflected in their different ability to bind to CD44.

\section{Conclusions}

The stability of LbL films constructed from PLL and HA depends on the HA size: more stable multilayers are generated by electrostatic interactions between longer HA and PLL. However, these systems are not stable enough when specific biomolecular interactions are at play, e.g. HA-CD44. In this context, crosslinking is an efficient strategy to increase the stability of the LbL systems. These processes affect not only the stability, but also the mechanical properties of the constructs: higher elastic and Young's moduli were determined for all crosslinked coatings when compared to the respective electrostatically deposited films. These changes were most pronounced for the crosslinked LbL films generated from HA of $6.4 \mathrm{kDa}$, for which significant reduction of the hydration and formation of denser films were observed. Finally, we demonstrate that PLL-HA chemical crosslinking does not compromise the HA bioactivity, i.e. the HA capacity to interact with CD44 in a $M_{\mathrm{w}}(\mathrm{HA})$-dependent manner. Overall, the properties of the reported LbL systems, such as stability, stiffness and biochemical responsiveness, support their use to target the cell surface via CD44 binding. In addition, these systems are valuable for the possible development of diagnostic devices (e.g. for CD44-overexpressing cancers) or for fundamental studies on the behavior of cancer cells.

\section{Conflicts of interest}

There are no conflicts to declare. 


\section{Acknowledgements}

The authors acknowledge the financial support from the European Commission's H2020 programme, under grant agreements H2020WIDESPREAD-2014-668983-FORECAST and H2020-WIDESPREAD01-2016-2017-739572-THE DISCOVERIES CTR. S. A. acknowledges the Portuguese Foundation for Science and Technology (FCT) for her PhD grant (SFRH/BD/112075/2015).

\section{References}

1 X. Liu, Z. Chen, R. Xu, R. Zhang, Z. Hu, F. Huang and Y. Cao, Small Methods, 2018, 2, 1700407.

2 K. Ren, L. Fourel, C. G. Rouviere, C. Albiges-Rizo and C. Picart, Acta Biomater., 2010, 6, 4238-4248.

3 X. Q. Liu and C. Picart, Adv. Mater., 2016, 28, 1295-1301.

4 S. Amorim, A. Martins, N. M. Neves, R. L. Reis and R. A. Pires, J. Mater. Chem. B, 2014, 2, 6939-6946.

5 N. Aggarwal, N. Altgarde, S. Svedhem, K. Zhang, S. Fischer and T. Groth, Langmuir, 2013, 29, 13853-13864.

6 M. Matsusaki, K. Kadowaki, Y. Nakahara and M. Akashi, Angew. Chem., 2007, 46, 4689-4692.

7 S. Amorim, D. S. da Costa, D. Freitas, C. A. Reis, R. L. Reis, I. Pashkuleva and R. A. Pires, Sci. Rep., 2018, 8, 16058.

8 M. S. Niepel, F. Almouhanna, B. K. Ekambaram, M. Menzel, A. Heilmann and T. Groth, Int. J. Artif. Organs, 2018, 41, 223-235.

9 T. Boudou, T. Crouzier, R. Auzely-Velty, K. Glinel and C. Picart, Langmuir, 2009, 25, 13809-13819.

10 D. Bütergerds, C. Cramer and M. Schönhoff, Adv. Mater. Interfaces, 2017, 4, 1600592.

11 M. Morga, Z. Adamczyk, S. Godrich, M. Ocwieja and G. Papastavrou, J. Colloid Interface Sci., 2015, 456, 116-124.

12 C. Shan, H. Yang, D. Han, Q. Zhang, A. Ivaska and L. Niu, Langmuir, 2009, 25, 12030-12033.

13 R. P. Richter, N. S. Baranova, A. J. Day and J. C. Kwok, Curr. Opin. Struct. Biol., 2018, 50, 65-74.

14 K. Haxaire, I. Braccini, M. Milas, M. Rinaudo and S. Perez, Glycobiology, 2000, 10, 587-594.

15 K. T. Dicker, L. A. Gurski, S. Pradhan-Bhatt, R. L. Witt, M. C. Farach-Carson and X. Jia, Acta Biomater., 2014, 10, 1558-1570.

16 B. P. Toole, Nat. Rev. Cancer, 2004, 4, 528-539.

17 M. P. Carvalho, E. C. Costa, S. P. Miguel and I. J. Correia, Carbohydr. Polym., 2016, 150, 139-148.

18 T. Chanmee, P. Ontong and N. Itano, Cancer Lett., 2016, 375, 20-30.

19 A. D. Theocharis, S. S. Skandalis, C. Gialeli and N. K. Karamanos, Adv. Drug Delivery Rev., 2016, 97, 4-27.

20 R. L. Wu, L. Huang, H. C. Zhao and X. P. Geng, J. Cancer Res. Clin. Oncol., 2017, 143, 1-16.

21 Z. K. Price, N. A. Lokman and C. Ricciardelli, Cancers, 2018, 10, 482 .

22 A. Szarpak, D. Cui, F. Dubreuil, B. G. De Geest, L. J. De Cock, C. Picart and R. Auzely-Velty, Biomacromolecules, 2010, 11, 713-720.
23 L. Richert, F. Boulmedais, P. Lavalle, J. Mutterer, E. Ferreux, G. Decher, P. Schaaf, J. C. Voegel and C. Picart, Biomacromolecules, 2004, 5, 284-294.

24 L. Shen, P. Chaudouet, J. Ji and C. Picart, Biomacromolecules, 2011, 12, 1322-1331.

25 L. T. Senbanjo and M. A. Chellaiah, Front. Cell Dev. Biol., 2017, 5, 18.

26 P. Parkkila, M. Elderdfi, A. Bunker and T. Viitala, Langmuir, 2018, 34, 8081-8091.

27 M. Westwood, T. R. Noel and R. Parker, Carbohydr. Polym., 2013, 94, 137-146.

28 R. Mendichi, A. G. Schieroni, C. Grassi and A. Re, Polymer, 1998, 39, 6611-6620.

29 B. B. Minsky, C. H. Antoni and H. Boehm, Sci. Rep., 2016, 6, 21608.

30 C. Kuehl, T. Zhang, L. M. Kaminskas, C. J. Porter, N. M. Davies, L. Forrest and C. Berkland, Mol. Pharmaceutics, 2016, 13, 1904-1914.

31 A. R. Patel, B. A. Kerwin and S. R. Kanapuram, J. Pharm. Sci., 2009, 98, 3108-3116.

32 X. Liu, D. Wu, S. Turgman-Cohen, J. Genzer, T. W. Theyson and O. J. Rojas, Langmuir, 2010, 26, 9565-9574.

33 S. L. Zhang, H. H. Bai and P. H. Yang, Chem. Commun., 2015, 51, 11449-11451.

34 G. Duner, E. Thormann and A. Dedinaite, J. Colloid Interface Sci., 2013, 408, 229-234.

35 F. Höök, Piezoelectric Sensors, Springer, 2007, vol. 5, pp. 425-447.

36 C. Picart, J. Mutterer, L. Richert, Y. Luo, G. D. Prestwich, P. Schaaf, J. C. Voegel and P. Lavalle, Proc. Natl. Acad. Sci. U. S. A., 2002, 99, 12531-12535.

37 P. Lavalle, C. Picart, J. Mutterer, C. Gergely, H. Reiss, J. C. Voegel, B. Senger and P. Schaaf, J. Phys. Chem. B, 2004, 108, 635-648.

38 R. Teixeira, R. L. Reis and I. Pashkuleva, Colloids Surf., B, 2016, 145, 567-575.

39 C. Picart, P. Lavalle, P. Hubert, F. J. G. Cuisinier, G. Decher, P. Schaaf and J. C. Voegel, Langmuir, 2001, 17, 7414-7424.

40 F. Hook, B. Kasemo, T. Nylander, C. Fant, K. Sott and H. Elwing, Anal. Chem., 2001, 73, 5796-5804.

41 N. Granqvist, H. Liang, T. Laurila, J. Sadowski, M. Yliperttula and T. Viitala, Langmuir, 2013, 29, 8561-8571.

42 K. Korhonen, N. Granqvist, J. Ketolainen and R. Laitinen, Int. J. Pharm., 2015, 494, 531-536.

43 N. Altgarde, E. Nileback, L. de Battice, I. Pashkuleva, R. L. Reis, J. Becher, S. Moller, M. Schnabelrauch and S. Svedhem, Acta Biomater., 2013, 9, 8158-8166.

44 P. Beldowski, T. Andrysiak, A. Mrela, Z. Pawlak, W. K. Auge, 2nd and A. Gadomski, Polymers, 2018, 10, 273.

45 A. S. Maharjan, D. Pilling and R. H. Gomer, PLoS One, 2011, 6, e26078.

46 C. Yang, M. Cao, H. Liu, Y. He, J. Xu, Y. Du, Y. Liu, W. Wang, L. Cui, J. Hu and F. Gao, J. Biol. Chem., 2012, 287, 43094-43107.

47 L. Y. Bourguignon, G. Wong, C. A. Earle and W. Xia, Cytoskeleton, 2011, 68, 671-693.

48 P. M. Wolny, S. Banerji, C. Gounou, A. R. Brisson, A. J. Day, D. G. Jackson and R. P. Richter, J. Biol. Chem., 2010, 285, 30170-30180. 